\title{
The influence of printing substrate on macro non-uniformity and line reproduction quality of imprints printed with electrophotographic process
}

\begin{abstract}
Print quality is very important for every printing technique. It depends on many different quality attributes. This research included analysis of macro non-uniformities and line reproduction. 16 different paper substrates printed by electrophotographic process were analyzed. They were separated in two groups: coated and uncoated papers. Analysis of macro non-uniformity showed that print mottle has lower values when printed on coated papers than on uncoated papers. Line reproduction analysis showed that the toner spreaded, during melting and fixation, on line edges for both types of paper. According to these results it can be concluded that paper substrate affects the macro non-uniformity and line reproduction, thus overall print quality.
\end{abstract}

\section{KEY WORDS}

digital printing, electrophotography, print quality, macro non-uniformity, line reproduction analysis

\author{
Đorđe Vujčić, \\ Branka Ružičić \\ University of Banja Luka, \\ Faculty of Technology, \\ Graphic engineering, Banja Luka, \\ Bosnia and Herzegovina \\ Corresponding author: \\ Đorđe Vujčić \\ e-mail:djordje.vujcic@unibl.rs
}

First recieved: 17.08.2016. Accepted: 22.11.2016.

\section{Introduction}

Digital printing has matured and it is now present in daily production. This is true for both the large format inkjet printing and digital commercial printing (with toner based and increasingly with ink jet technique). In the graphic arts industry in particular the latter use case shows tremendous growth figures where small and medium run lengths are taken over increasingly from the offset market (Kraushaar, 2010). As digital printing industry grows every day a lot of work has been done in improving and developing new technologies and products. This increased growth demands higher level of quality assessment in order to be able to compare different products and technologies and evaluate them (Pedersen et al., 2011). Most production digital printing processes depend on the use of certified paper to perform to their best capacity. Any adjustments that need to be made to the actual press require the intervention of technical support personnel other than the press operator (Chung \& Rees, 2007). Print quality is very important in each printing technology, and also for digital printing (Rilovski et al., 2012). A common way for analyzing the print quality is to quantitatively assess image color and tone value reproduction using corresponding measuring device. This way of analyzing print quality is easy, since tone and color are easily perceptible, but they are not enough for determining print quality (Dhopade, 2009; Kiurski \& Oros, 2012). Several experiments proved that print quality is not a monotonic function of hue, saturation and brightness (Fedorovskaya, Ridder \& Blommaert, 1997; Pedersen et al., 2009). Quantitative print quality assessment depends on a number of quality attributes (Pedersen et al., 2011; Rilovski et al., 2012). There are several of them such as contrast, sharpness, macro-uniformity, etc., which are not associated with tone and color but have considerable influence on print quality. They are directly connected with line and dot quality, which are structural elements of any image (Dhopade, 2009). So far many researches have been done that confirmed the importance of different quality attributes, but there is no overall agreement which of them are most important (Pedersen et al., 2011; Rilovski et al., 2012). One of the reason is multidimensionality and complexity of image quality (Pedersen et al., 2011).

Lindberg (Lindberg, 2004) in his study used 12 different quality attributes to evaluate overall print quality. It 
is preferred to use all attributes for determining print quality, but for evaluating image quality in industrial enviroment using some of them is more suitable. Lindberg discovered that print mottle and color gamut strongly affect the perception of the image quality. Also, color shift and sharpness have great influence on perceived quality (Petterson, 2005; Rilovski et al., 2012). So, according to Lindberg we can reduce number of quality attributes to four mentioned, which corresponds to Engeldrum's statement that observers will not perceive more than five quality attributes at the same time (Rilovski et al., 2012). Pedersen et al. in their research reduced quality attributes built on existing attributes from the literature to following six: sharpness, color, lightness, artefacts, contrast, and physical (Pedersen et al., 2011).

Petersson also realized importance of print mottle in print quality, as well as color gamut, color shift and sharpness(Petterson, 2005). Non-uniformity of printing density called print mottle stands for one of the most upsetting printing trouble that influence overall print quality (Fahlcrantz, 2005; Kawasaki \& Ishisaki, 2009). We can explain print mottle as a term that describes optical heterogeneity, unevenness in optical density and print gloss, and it can appear in solid tones or smooth image areas (Rilovski et al., 2012). According to Fahlcrantz mottle is defined as perceived inhomogeneities in the print due to unintentional variations in the lightness of the printed surface when it is viewed under homogeneous illumination (Fahlcrantz, 2005). Evaluating overall product quality depends on the uniformity of homogeneous image regions (Lindberg, 2004).

Print mottle is caused by uneven toner transfer and adhesion, which depends on substrate and toner properties, and by printing press conditions, e.g. toner fixing (Rilovski et al., 2012). Thus, print density and also print mottle will arise if the toner adhesion and the fixation of the colorants are not equal over all paper surface (Petterson, 2005). It can be concluded that the paper, the toner and the process are three most influential factors affecting toner adhesion and fixation (Rilovski et al., 2012).

Attention in this research is focused on analysis of macro non-uniformities, e.g. print mottle and line reproduction quality. Print mottle parameters of interest in this research are: contrast, correlation, entropy, energy and homogeneity. It was found that low contrast, low correlation, low entropy, high energy and high homogeneity correspond to uniform grey level distribution, i.e. low print mottle (Chen, 1998; Hladnik \& Lazar 2011; Ružičić et al., 2014). Also, important parameter of print quality is line reproduction quality, which consists of line width and its variations, raggedness and sharpness (Stančić et al., 2013a). Line raggedness point out the straightness of a printed line. Any geometric distortion is recognized as an unwanted feature of a line, and therefore reduces the quality of the printed image (Dhopade, 2009). Line raggedness can be described by measuring area and perimeter of lines and comparing obtained values with ideal. Exceeding line raggedness results in low printing sharpness and leads to unclear or bold text (Stančić et al., 2013a). Lines become wider because of ink bleeding. Hence, evaluating the line width modifications could define the bleeding degree (Stančić et al., 2012).

The aim of this study was to find out how different substrates effect on print quality in electrophotography. Quality attributes print mottle and line quality was analyzed. The method of digitally analyzed scanned printed images in specified softwares was used for estimation of these quality attributes.

\section{Methods and Materials}

This research included 16 different paper substrates. They can be separated in two groups: coated and uncoated. In Table 1 are shown coated papers and in Table 2 uncoated.

Table 1

Coated paper substrates used in research (Ecopaper, 2015a; Ecopaper, 2015b)

\begin{tabular}{|c|c|c|c|c|c|c|c|c|}
\hline $\begin{array}{l}\frac{n}{\pi} \\
-\frac{\pi}{2} \\
\frac{ \pm}{\pi} \\
\frac{\pi}{0} \\
\frac{2}{d} \\
\frac{0}{0}\end{array}$ & 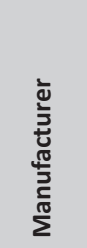 & 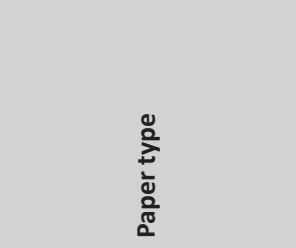 & 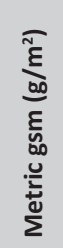 & 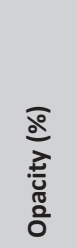 & 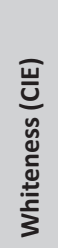 & 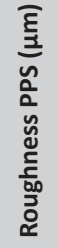 & 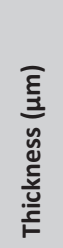 & 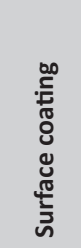 \\
\hline Coated paper 1 & Sappi & Kunstdruck Quatro silk & 115 & 95 & 121 & 1,7 & 95 & Matte \\
\hline Coated paper 2 & Sappi & Kunstdruck Quatro gloss & 115 & 93 & 117 & 0,9 & 84 & Gloss \\
\hline Coated paper 3 & Sappi & Kunstdruck Quatro silk & 130 & 96 & 121 & 1,7 & 108 & Matte \\
\hline Coated paper 4 & Sappi & Kunstdruck Quatro gloss & 130 & 94 & 117 & 0,9 & 94 & Gloss \\
\hline Coated paper 5 & Sappi & Kunstdruck Quatro silk & 150 & 97,5 & 121 & 1,7 & 125 & Matte \\
\hline Coated paper 6 & Sappi & Kunstdruck Quatro gloss & 150 & 95,5 & 117 & 0,9 & 110 & Gloss \\
\hline Coated paper 7 & Sappi & Kunstdruck Quatro silk & 350 & 99,5 & 121 & 2,0 & 347 & Matte \\
\hline Coated paper 8 & Sappi & Kunstdruck Quatro gloss & 350 & 99 & 121 & 0,8 & 273 & Gloss \\
\hline
\end{tabular}




\section{Table 2}

Uncoated paper substrates used in research (UPM, 2016)

\begin{tabular}{|c|c|c|c|c|c|c|c|c|}
\hline $\begin{array}{l}\frac{n}{\pi} \\
\frac{0}{2} \\
\frac{ \pm}{\pi} \\
\frac{\pi}{2} \\
\frac{1}{d} \\
\frac{0}{0}\end{array}$ & 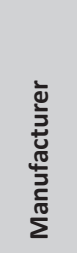 & $\begin{array}{l}\searrow \\
\frac{0}{2} \\
\frac{1}{0} \\
\frac{0}{0}\end{array}$ & 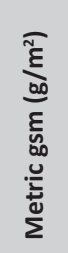 & 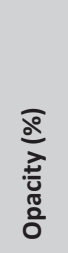 & 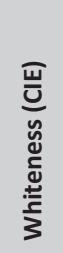 & 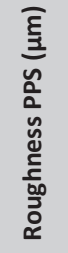 & 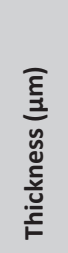 & 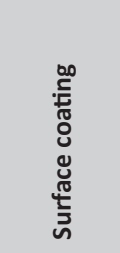 \\
\hline Uncoated paper 1 & UPM & Maxi offset & 70 & 90 & 150 & 250 & 90 & Uncoated \\
\hline Uncoated paper 2 & UPM & Maxi offset & 80 & 92,5 & 150 & 250 & 102 & Uncoated \\
\hline Uncoated paper 3 & UPM & Maxi offset & 90 & 94,5 & 150 & 250 & 114 & Uncoated \\
\hline Uncoated paper 4 & UPM & Maxi offset & 100 & 95,5 & 150 & 250 & 125 & Uncoated \\
\hline Uncoated paper 5 & UPM & Maxi offset & 140 & 98 & 150 & 250 & 163 & Uncoated \\
\hline Uncoated paper 6 & UPM & Maxi offset & 190 & 99,5 & 150 & 250 & 207 & Uncoated \\
\hline Uncoated paper 7 & UPM & Maxi offset & 250 & 99,7 & 150 & 250 & 275 & Uncoated \\
\hline Uncoated paper 8 & UPM & Maxi offset & 300 & 99,9 & 150 & 250 & 330 & Uncoated \\
\hline
\end{tabular}

The samples were printed with digital printing technique using electrophotographic printer Xerox Color560. This printer uses powder toner, which formulation is shown in Table 3.

Table 3

Xerox Color560 toner formulation (Xerox, 2016)

\begin{tabular}{l|c|}
\hline Chemical name & Weight (\%) \\
\hline Polyester resin & $60-70$ \\
\hline Ferrite & $10-20$ \\
\hline Paraffin wax & $1-10$ \\
\hline Pigment (Cyan, Magenta, Yel- & $0-10$ \\
\hline low or Carbon black) & $1-5$ \\
\hline Amorphous silica & $<1$ \\
\hline Titanium dioxide & \\
\hline
\end{tabular}

Test image, used in research, was created using Adobe Illustrator CS6 software. Test image dimensions were $148,5 \times 210 \mathrm{~mm}$ and contains different elements used for print quality control. Elements used for obtaining the results were $2.54 \times 2.54 \mathrm{~cm}$ solid tone patches and $2 \mathrm{pt}$ lines (Figure 1). In previous researches solid tone patches dimensions $2.54 \times 2.54 \mathrm{~cm}$ were used for obtaining the results of print mottle (Stančić et al., 2013a; Stančić, Kašiković \& Novaković, 2013; Stančić et al., 2013b; Ružičić et al., 2014; Jurič et. al, 2015). In another research (Milošević et al., 2013) solid tone patches dimensions $1 x$ $1 \mathrm{~cm}$ were used for print mottle. Since previous researches used patches different sizes in this research solid tone patches dimensions $2.54 \times 2.54 \mathrm{~cm}$ were chosen.
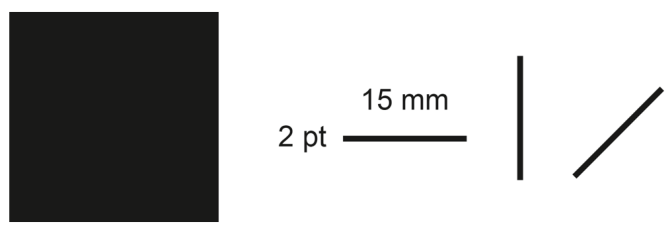

Print mottle assessment of the prints was conducted via GLCM image processing method (Gray Level Co-occurrence Matrix), using MATLAB software, after which five solid-tone surface uniformity parameters were extracted. It uses a matrix that keeps track of how often different combinations- pairs- of pixel intensity (gray level) values in a specific spatial relationship and distance occur in an image, which makes it possible to compute various first and second order statistical parameters or texture measures (Milošević et al., 2013).

After printing, the samples were scanned usingHP Scanjet 3670 Scanner. Scanning resolution was set on $1200 \mathrm{spi}$ and all auto functions were turned off. Then, scanned images were scaled to dimensions of $500 x$ 500 pixels, using Adobe Photoshop CS6 software, and saved as TIFF files, in order to prepare the samples for subsequent GLCM image processing and extraction of five solid-tone surface uniformity parameters (contrast, correlation, entropy, energy and homogeneity).

In order to evaluate line quality, the area and perimeter of $2 \mathrm{pt}$ linewere measured and compared with area and perimeter of ideal line created on a computer using Illustrator CS6 software in raster in resolution of 1200 ppi. These values were calculated using ImageJ software, implemented in Java for the creation, visualization, editing, processing, and image analysis (Rasband, 1997).

In order to achieve higher accuracy of the measurement results, more samples were measured with repetition on the individual samples. As measurement results were taken arithemtic means of ten times measured numerical values.

» Figure 1: The part of test image used in the research 


\section{Results and Discussion}

\section{Macro non-uniformity analysis}

In Figure 2 are shown different solid-tone surface uniformity parameters (contrast, correlation,entropy, energy and homogeneity) for different substrates printed with digital printing technology for black color. It can be noticed that values of contrast are low for both coated and uncoated papers, but they are lower in case of coated papers. Correlation has high values for both types of papers. Entropy has low values in most cases of coated papers and high values in case of uncoated papers. Energy has high values for coated papers and mostly low values for uncoated papers. And, at the end, homogeneity has high values for both types of papers. These results show that print mottle is higher on uncoated papers because correlation and entropy have high values, and energy low. It can also be noticed that for coated papers all values except correlation correspond with low print mottle. Correlation should have low values but in this case it is opposite.

The reason why print mottle is lower when printing on coated then on uncoated paper is correlated with paper surface and roughness. Coated papers have smoother surface structure and they are less porous, so toner is evenly distributed over the paper surface. Uncoated papers are more porous, so toner is filling voids, during melting and fixation, which results in uneven print over the paper surface. Color is not homogenous and even over imprint surface, so this unequal fixation of toner on the surface of paper leads to higher values of print mottle.

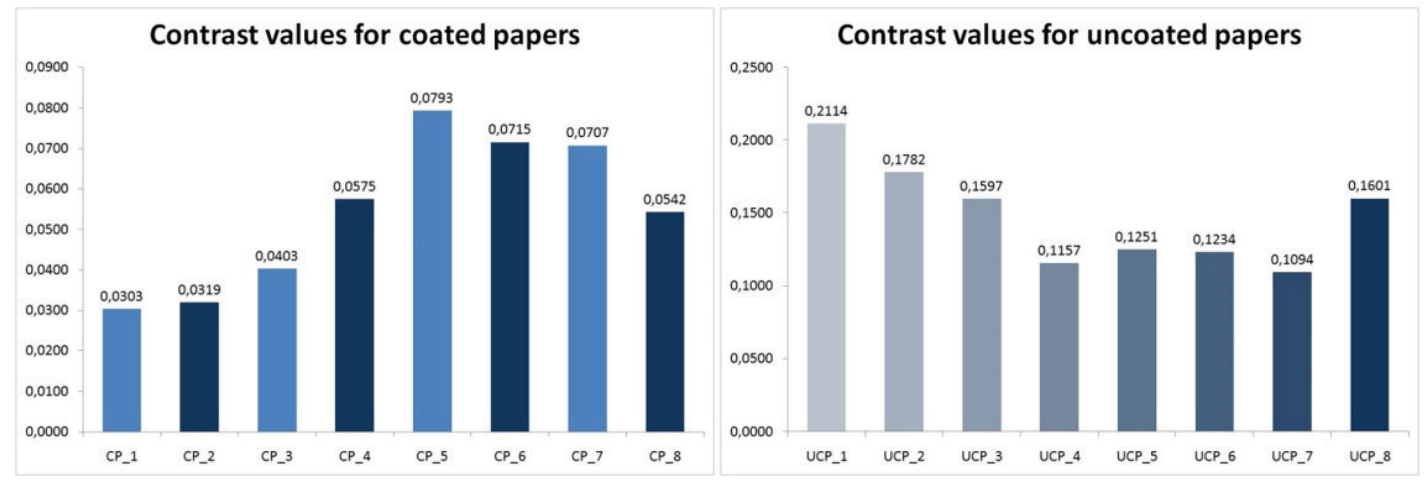

a)
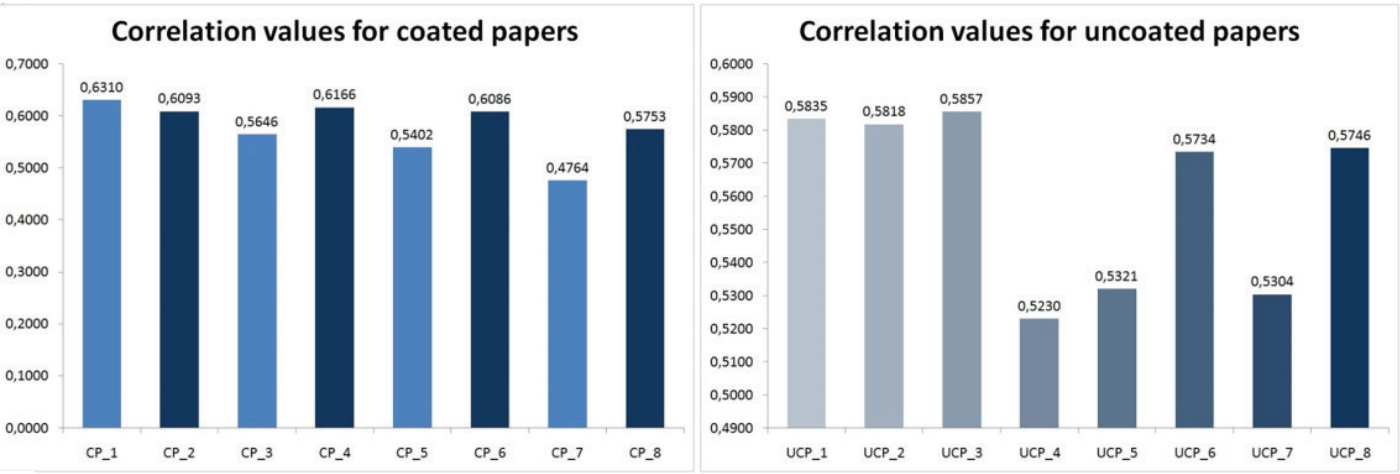

b)
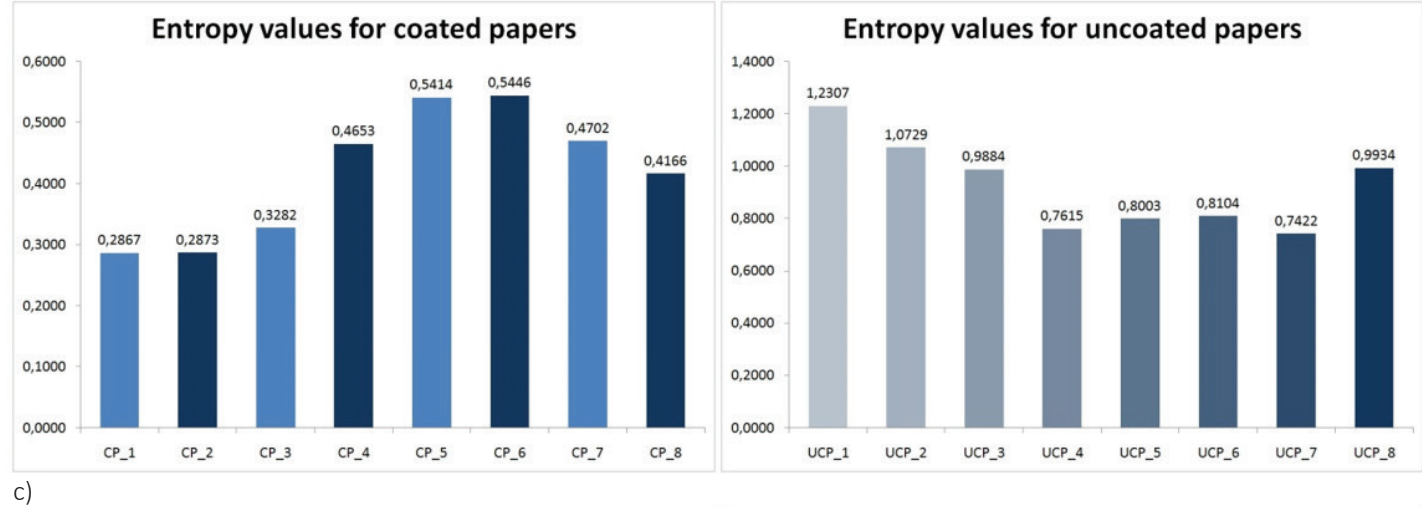

» Figure 2 (part 1): Values of different print mottle parameters: (a) Contrast; (b) Correlation; (c) Entropy; (d) Energy; (e) Homogeneity (Note: CP stands for coated papers, and UCP stands for uncoated papers) 


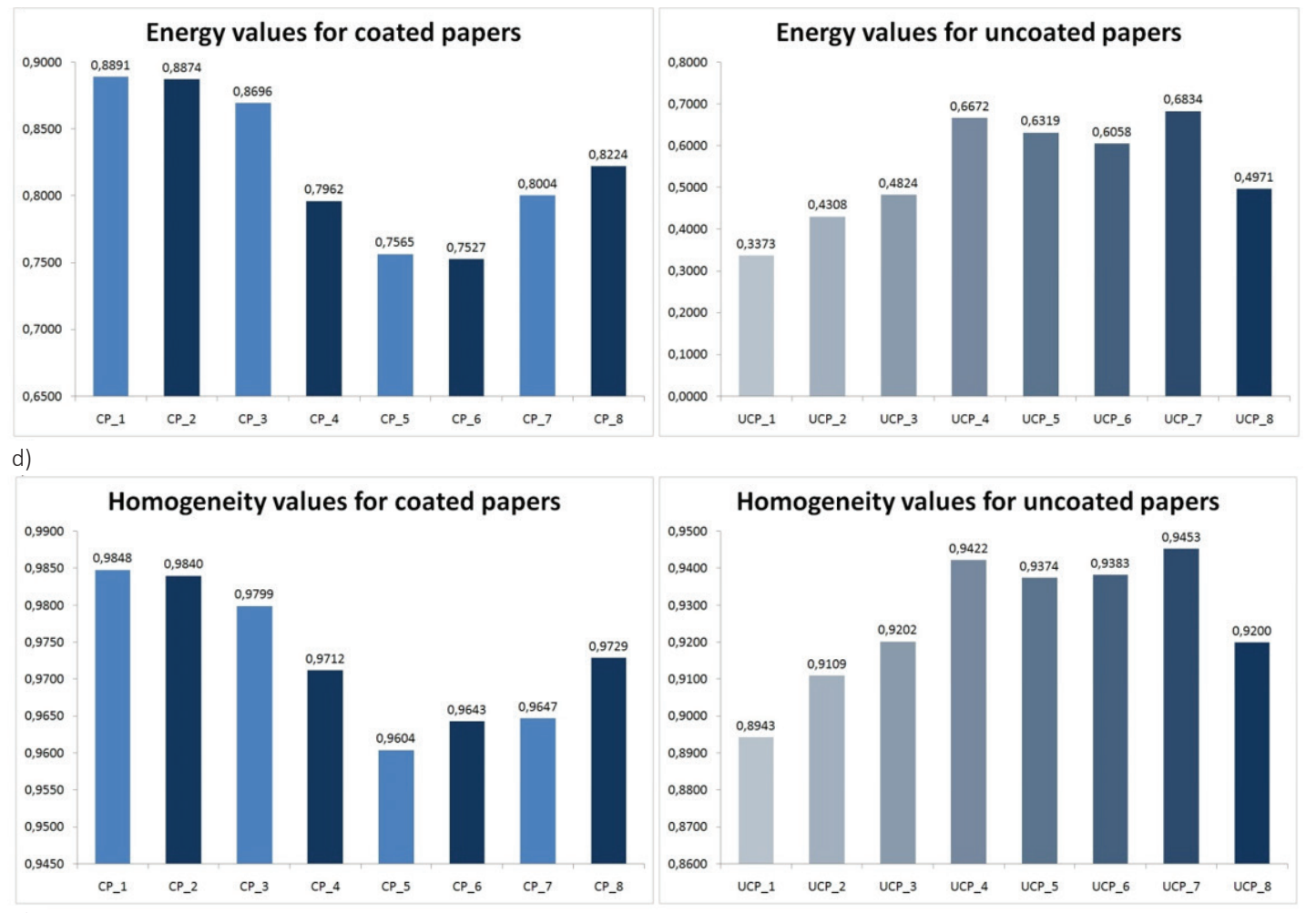

e)

» Figure 2 (part 2): Values of different print mottle parameters: (a) Contrast; (b) Correlation; (c) Entropy; (d) Energy; (e) Homogeneity (Note: CP stands for coated papers, and UCP stands for uncoated papers)

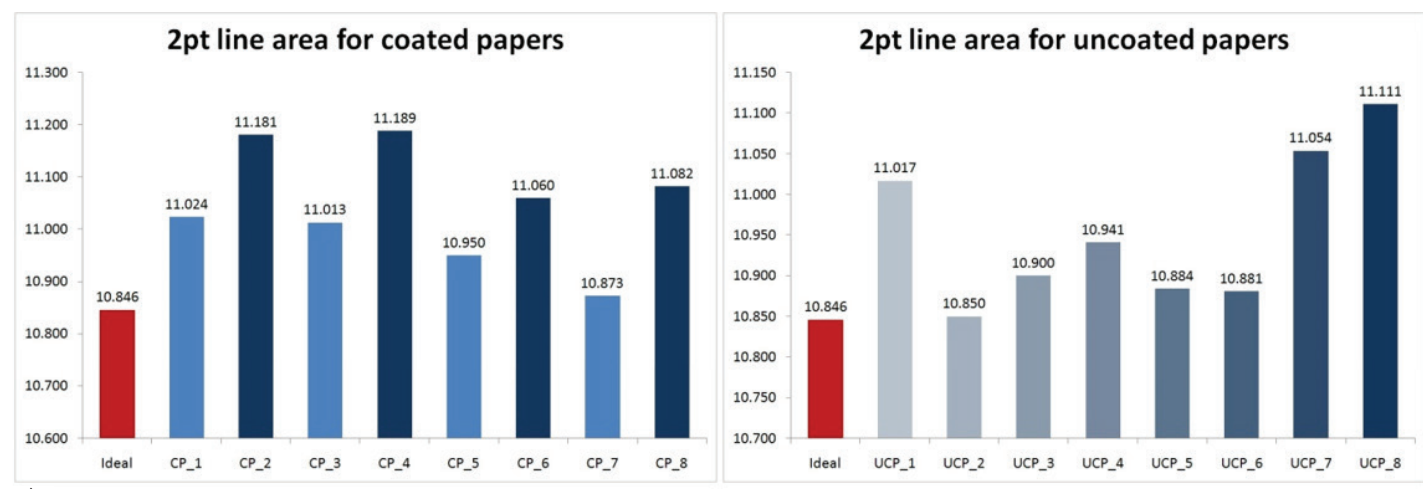

a)

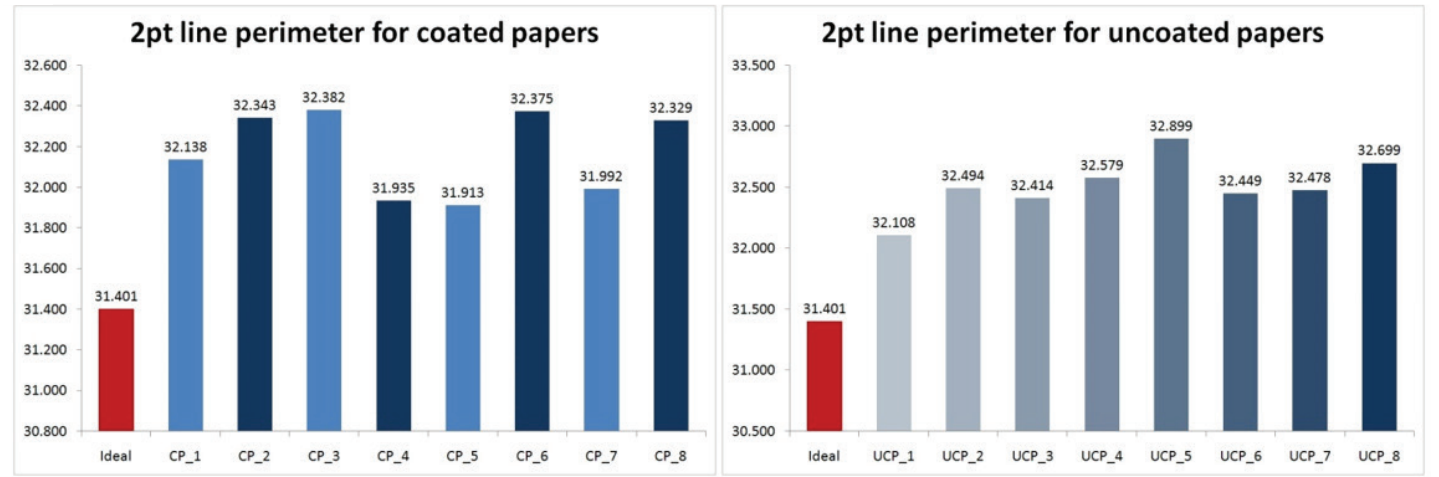

b)

» Figure 3: Graphic representation of movements of 2pt line for coated and uncoated papers: a) Area values; b) Perimeter values(Note: CP stands for coated papers, and UCP stands for uncoated papers) 
When comparing values of print mottle for matte and gloss coated papers it can be seen that they are almost equal. Values of all 5 parameters for both types of papers are similar, so it can be concluded that type of coating does not significantly influence print mottle.

\section{Line reproduction analysis}

Values of area and perimeter for different substrates printed with digital printing technology for black color are shown in Figure 3. Line area and perimeter results indicate that all paper types show a difference in a relation to an ideal text area and perimeter. All values are higher than ideal which shows that toner spreaded, during melting and fixation, on line edges. Also, there is no significant difference between coated and uncoated papers.

\section{Conclusions}

The aim of this paper is to point out the influence of different substrateson print quality in digital printing technology. Different paper types, coated and uncoated, were printed with digital printing technique and prints were examined. In order to define the influence of the substrate, the basic attributes of print quality were analyzed: macro non-uniformity and line reproduction. Macro non-uniformity parameter obtained using GLCM image analysis method showed that print mottle has lower values when printing on coated papers than on uncoated papers. Also, in case of coated papers we can notice that values of correlation are high which correspond to high print mottle. We can also notice that coated paper with lowest gsm has the lowest values of print mottle. In case of uncoated papers we can notice that paper of $250 \mathrm{~g} / \mathrm{m}^{2}$ has the lowest print mottle. For uncoated papers correlation and entropy have high values, and energy for some papers has low value, so print mottle, generally, has high values.

Paper surface and roughness are very important characteristics that affect print mottle. Since coated papers have smoother surface adhesion and fixation of toner is more equal when compared to uncoated papers which have more porous surface. This results in lower values of print mottle when measured on coated papers. Also, there is no significant difference in print mottle between matte and gloss coated papers which leads to conclusion that coating type does not play significant role in print mottle.

Line reproduction analysis showed that that toner spreaded, during melting and fixation, on line edges since all values of line area and perimeter for all types of paper are higher than ideal. In case of line quality there is no important difference between coated and uncoated papers.
According to results of analysis it can be concluded that paper substrate affects the print quality. Further research should be focused on analyzing more print quality parameters, more different types of papers and they should also include other process colors.

\section{References}

Chen, Y. (1998) Image Analysis Methods for Paper Formation Evaluation. MSc thesis. University of Toronto.

Chung, R. \& Rees, M. (2007) A Survey of Digital and Offset Print Quality Issues. Rochester, Printing Industry Center at RIT. Available from: http://scholarworks. rit.edu/books/49 [Accessed 16th May 2016].

Dhopade, A. (2009) Image Quality Asessment according to ISO 13660 and ISO 19751. Rochester, Printing Industry Center at RIT.

Ecopaper (2015a) Product information sheet: Quatro gloss. Available from: http://www.ecopaper.it/images/ pdf/quatro-gloss.pdf [Accessed 14th November 2016].

Ecopaper (2015b) Product information sheet: Quatro silk. Available from: http://www.ecopaper.it/images/ pdf/quatro-silk. pdf [Accessed 14th November 2016].

Fahlcrantz, C. (2005) On the Evaluation of Print Mottle. PhD thesis. KTH Royal Insistute of Technology.

Fedorovskaya, E. A., Ridder, H. \& Blommaert, F. J. J. (1997) Chroma variations and perceived quality of color images of natural scenes. Color research and application. 22 (2), 96- 110. Available from: doi: 10.1002/(SICI)1520-6378(199704)22:2<96::AIDCOL5>3.0.CO;2-Z [Accessed 20th May 2016].

Hladnik, A. \& Lazar, M. (2011) Paper and board surface roughness characterization using laser profilometry and gray level cooccurrence matrix. Nordic Pulp and Paper Research Journal. 26 (1), 99-105. Available from: doi: 10.3183/NPPRJ-201126-01-p099-105 [Accessed 20th May 2016].

Jurič, I., Kašiković, N., Stančić, M., Novaković, D., Vladić, G. \& Majnarić, I. (2015) The influence of heat treatment on print mottle of screen printedtextile knitted fabrics. Applied Thermal Engineering. 90, 215-220. Available from: doi: 10.1016/j.applthermaleng.2015.07.013 [Accessed 10th June 2016].

Kawasaki, M. \& Ishisaki, M. (2009) Investigation into the Cause of Print Mottle in Halftone Dots of Coated Paper: Effect of Optical Dot Gain Non-uniformity. Available from: http://www. tappi.org/content/06IPGA/5-4\%20Kawasaki\%20 M\%20Ishisaki.pdf [Accessed 12th June 2016].

Kiurski, J. \& Oros, I. (2012) The influence of pH/ conductivity of fountain solution on dot circularity, line and text raggedness. Journal of Graphic Engineering and Design. 3 (2), 1-7. Available from: http://www.grid.uns.ac.rs/jged/download. php?fid=125 [Accessed 12th June 2016]. Kraushaar, A. (2010) Process Standard Offset print [PSO] for Digital Printing? Available from: https:// 
www. fogra. org/index. php? menuid $=48 \&$ download $\mathrm{id}=222 \&$ reporeid=197 [Accessed 12th June 2016].

Lindberg, S. (2004) Perceptual determinants of print quality. PhD Thesis. Stockholm University: Department of Psychology.

Milošević, R., Kašiković, N., Novaković D., Stančić M. \& Adamović, S. (2013) Investigation of the Printing Pressure Level Application Influence on Sheet-fed Offset Print Quality. Machine Design. 5 (4), 171-176.

Pedersen, M., Bonnier, N., Hardeberg, J. \& Albregtsen, F. (2009) Attributes of a new image quality model for color prints. In: Murdoch, M. J. (ed.) CIC 09: Proceedings of 17th Color and Imaging Conference, Albuquerque, New Mexico. ClCO9, 9-13 November 2009. Society for Imaging Science and Technology, Springfield, Ilinois. pp. $204-209$.

Pedersen, M., Bonnier, N., Hardeberg, J. \& Albregtsen, F. (2011) Image quality metrics for the evaluation of print quality. In: Famand, S.P. \& Gaykema, F. (eds.) IS\&T/SPIE ELECTRONIC IMAGING: IS\&T/ SPIE ELECTRONIC IMAGING Proceedings volume 7867, Image quality and system performance VIII, IS\&T/SPIE ELECTRONIC IMAGING, San Francisco, California. 23 -27 January 2011. Bellingham, Washington, SPIE Publictions. pp. 1-19.

Petterson, J. (2005) A Review of Perceptual Image Quality. Disertation. Linköpings Universitet: Department of Science and Technology.

Rasband, W. S. (1997) ImageJ [Software] U. S. National Institutes of Health. Available from: http://rsb.info.nih.gov/ij/.

Rilovski, I., Karlović, I., Novaković, D. \& Tomić, I. (2012) Influence of Paper Surface Properties and Toner Type on Digital Print Mottle. Celuloză şi Hârtie. 61 (2), 4-9.

Ružičić, B., Stančić, M., Milošević, R. \& Sadžakov, M. (2014) Influence of Substrate Thickness on the Reproduction Quality of Screen Printed Polymer Materials. In: Novaković, D. (ed.) GRID 2014: Interna- tional Symposium on Graphic Engineering and Design: Proceedings of the 7th International Symposium GRID 2014, 13-14 November 2014, Novi Sad, Serbia. Novi Sad, Faculty of Technical Sciences. pp. 239-245.

Stančić, M., Novaković, D., Kašiković, N., Vukmirović, V. \& Ružičić, B. (2013a) Influence of material composition on print quality digitally printed textile substrates. Tekstilna industrija. 1/2013, 37-43.

Stančić, M., Kašiković, N., \& Novaković, D. (2013) Influence of process colours on the print quality digitally printed textile substrates. Glasnik hemičara, tehnologa i ekologa Republike Srpske. 9, 59-66.

Stančić, M., Kašiković, N., Novaković, D., Milošević, R., \& Grujić D. (2013b) Thermal Load Effect on Print Quality of Ink Jet Printed Textile Materials. Journal of Graphic Engineering and Design. 4 (2), 27-33. Available from: http://www.grid.uns.ac.rs/jged/download. php?fid=138 [Accessed 14th November 2016].

Stančić, M., Novaković, D., Tomić, I. \& Karlović, I. (2012) Influence of Substrate and Screen Thread Count on Reproduction of Image Elements in Screenprinting. Acta Graphica, 23 (1-2), 1-12. Available from: http:// www.actagraphica.hr/index.php/actagraphica/ article/view/78 [Accessed 14th November 2016].

UPM. (2016) UPM Fine. Available from: http:// www.upmpaper.com/papers/Pages/Paper.aspx?ppid=490\& region=EMEA\&language $=e n-g b$ [Accessed 14th November 2016].

Xerox. (2016) Safety data sheet: Replenisher-Black/ Cyan/Magenta/Yellow. Available from: https:// www.xerox.com/download/ehs/msds/P-7010. en-us.pdf [Accessed 14th November 2016].

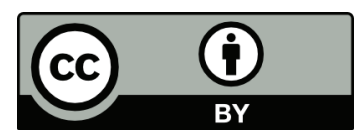

(C) 2016 Authors. Published by the University of Novi Sad, Faculty of Technical Sciences, Department of Graphic Engineering and Design. This article is an open access article distributed under the terms and conditions of the Creative Commons Attribution license 3.0 Serbia (http://creativecommons.org/licenses/by/3.0/rs/). 